\title{
A escolarização de alunos com deficiência intelectual: uma análise da aplicação do Plano de Desenvolvimento Educacional Individualizado ${ }^{1}$
}

\author{
Márcia Denise Pletsch \\ Universidade Federal Rural do Rio de Janeiro
}

Rosana Glat Universidade do Estado do Rio de Janeiro

\section{Resumo}

O texto apresenta uma discussão sobre a escolarização de alunos com deficiência intelectual em diferentes contextos educacionais. 0 foco do estudo é o processo de ensino e aprendizagem e o desenvolvimento desses sujeitos a partir do referencial sócio-histórico-cultural de Vigotski. A pesquisa, de natureza qualitativa, foi realizada em três escolas públicas localizadas no Rio de Janeiro: duas escolas regulares municipais e uma escola especializada estadual. A coleta de dados foi realizada ao longo de aproximadamente quatro anos. Foram analisadas as trajetórias escolares de cinco alunos com deficiência intelectual por meio da aplicação, entre outros procedimentos, do Plano de Desenvolvimento Educacional Individualizado (PDEI). Em síntese, os resultados evidenciaram a precariedade do processo de ensino e aprendizagem oferecido a alunos com deficiência intelectual, independente da modalidade de escolarização e a falta de conhecimentos dos professores no que se refere às especificidades educacionais desses sujeitos. 0 estudo apontou também a importância do planejamento de estratégias pedagógicas tendo como base a aplicação do PDEl para favorecer o processo de aprendizagem e inclusão escolar deste alunado.

Palavras-chave: Deficiência intelectual. Ensino e aprendizagem. Políticas de inclusão escolar. Plano de desenvolvimento educacional individualizado.

1. Dados condensados dessa pesquisa que contou com financiamento do CNPq, FAPERJ e CAPES foram apresentados na 34 Reunião Anual da Associação Nacional de Pós-Graduação e Pesquisa em Educação realizada em outubro de 2011 em Natal/RN. 


\section{The learning process of students with intellectual disabilities: an analysis of the application of the Individualized Educational Development Plan}

The present text presents a discussion about schooling of students with intellectual disabilities, in different educational settings. The focus of the study is the teaching-learning process and the development of these subjects, based on the socio-historical-cultural framework of Vygotsky. The qualitative research was undertaken in three public schools located in Rio de Janeiro: two regular units from the city school system and one special state school. The data was collected during approximately four years. The school trajectories of five students with intellectual disabilities were analyzed through the application of, among other procedures, the Individualized Educational Development Plan (IEDP). In short, the results showed the precariousness of the teaching-learning process offered to these students, regardless of the type of schooling; and the lack of knowledge of the teachers in regards to the educational specificities of these subjects.

Keywords: Intellectual disabilit. Teaching-learning process. School inclusion policies. Individualized Educational Development Plan.

\section{La escolarización de los alumnos con discapacidad intelectual: una revisión de la aplicación del Plan Individualizado de Desarrollo Educacional (PIDE)}

Este artículo presenta un análisis de la educación de estudiantes con discapacidad intelectual en diferentes contextos educativos. El foco del estudio es el proceso de enseñanza y aprendizaje y el desarrollo de estos temas a partir de la referencia sociohistórico-cultural de Vigotski. La investigación, de carácter cualitativo, se llevó a cabo en tres escuelas públicas de Río de Janeiro: dos escuelas normales municipales y una escuela especializada provincial. La recolección de datos se realizó durante aproximadamente cuatro años. Se analizaron las trayectorias de los cinco estudiantes con discapacidad intelectual a través de la aplicación, entre otros procedimientos, del Plan Individualizado de Desarrollo Educacional. En resumen, los resultados pusieron de manifiesto la precariedad de la enseñanza y el aprendizaje que se ofrece a los estudiantes con discapacidad intelectual, independientemente del tipo de escolaridad y la falta de maestros con los conocimientos específicos sobre las deficiencias. El estudio también señaló la importancia de la planificación de estrategias de enseñanza basadas en la aplicación del PIDE para facilitar el proceso de aprendizaje y la escolarización de los alumnos

Palabras clave: Discapacidad intelectual. Enseñanza y aprendizaje. Políticas de inclusión escolar. Plan Individualizado de Desarrollo Educacional. 


\section{Introdução}

De acordo com dados recentes do Ministério da Educação (Brasil, 2008, 2009), dos 700.824 alunos matriculados em modalidades de educação especial, 330.794 laproximadamente 47\%) apresentam deficiência intelectual. Embora a política educacional vigente privilegie a inclusão de alunos com necessidades educacionais especiais ${ }^{2} \mathrm{em}$ turmas comuns, e, inclusive, incentive a descontinuidade dos serviços especializados substitutivos (Brasil, 2008; 2009), alunos com deficiência intelectual continuam, majoritariamente, matriculadas em classes e/ou escolas especiais (226.429, num total de 330.794, mais de 68\%) (Brasil, 2008) .

A inclusão de alunos com deficiência intelectual em turmas comuns já vem acontecendo em nosso país desde a década de 1990. No entanto, a partir da publicação da Política Nacional de Educação Especial na Perspectiva da Educação Inclusiva (Brasil, 2008) e das Diretrizes do Atendimento Educacional Especializado na Educação Básica, modalidade de educação especial (Brasil, 2009), esta questão tem recebido atenção especial nas discussões acadêmicas e até mesmo na mídia4.

Em âmbito internacional, muito do debate tem privilegiado os avanços na pesquisa científica, destacando-se a substituição do termo deficiência mental por deficiência intelectual. Esse "novo" termo vem sendo disseminado desde a Conferência Internacional sobre Deficiência Intelectual, realizada em 2001, no Canadá, por recomendação da International Association for the Scientific Study of Intellectual Disabilities (IASSID) - Associação Internacional de Estudos Científicos das Deficiências Intelectuais. Todavia, somente em 2010 a Associação Americana de Deficiência Intelectual e Desenvolvimento (AADID), anteriormente denominada Associação Americana de Retardo Mental (AARM), incorporou o novo conceito ao seu modelo de classificação e sistema de suportes. Vale comentar que as proposições da AADID são usadas como referência para a elaboração de diferentes sistemas de classificação, como a Classificação Internacional do Funcionamento da Deficiência e da Saúde (CIF), a Classificação Estatística Internacional de Doenças e Problemas Relacionados com a Saúde (CID-10) lambos da Organização Mundial de Saúde - OMS) e o Manual de Diagnóstico e Prática Profissional em Retardo Mental da Associação Americana de Psicologia (APA).

2. Neste texto, o termo "necessidades educacionais especiais" é empregado para designar alunos com deficiências mental/intelectual, sensoriais (surdos, deficiência auditiva, cegos ou baixa visão), transtornos globais do desenvolvimento, altas habilidades/superdotação, deficiências físicas múltiplas e outras condições atípicas do desenvolvimento.

3. No momento da redação deste artigo, os dados de 2010 e 2011 ainda não haviam sido disponibilizados pelo Ministério da Educação.

4. Ainda a esse respeito, cabe apontar que, em novembro de 2011, a Presidente Dilma Rousseff apresentou o Programa Viver sem Limites, assim como o Decreto $n^{0} 7.611 / 2011$, que revogou o Decreto $n^{\circ} 6.571 / 2008$ - este tratava do "atendimento educacional especializado" numa perspectiva de apoio e complemento aos serviços de educação inclusiva. 
De acordo com diferentes autores, não se trata simplesmente da troca de uma expressão por um sinônimo menos estigmatizante. Esta mudança de terminologia fruto de amplo debate nos meios científicos internacionais - representa um novo paradigma em termos de definição do construto da deficiência intelectual, em processo desde a definição e classificação apresentada pela então AAMR em 2002 (Schalock et al., 2007; Wehmeyer et al., 2010; Alonso; Schalock, 2010)5.

Para compreender como a terminologia apresentada pela AAMR, agora AADID, vem sendo incorporada nas discussões acadêmicas e nas propostas educacionais dirigidas para as pessoas com deficiência intelectual, temos realizado desde 2006 pesquisas de campo analisando trajetórias escolares para avaliar o processo de ensino e aprendizagem e o desenvolvimento desses sujeitos em diferentes contextos educacionais. 0 objetivo deste texto é justamente apresentar dados de alguns desses estudos. Para tal, apresentaremos sucintamente uma discussão sobre a escolarização de alunos com deficiência intelectual em diferentes contextos educacionais. 0 foco das reflexões recai sobre 0 processo de ensino e aprendizagem e o desenvolvimento desses sujeitos a partir do referencial sócio-histórico-cultural de Vygotskib e seus seguidores ${ }^{7}$.

Os estudos que serão aqui discutidos foram realizados em três escolas públicas localizadas no Rio de Janeiro, duas escolas regulares municipais e uma escola especializada estadual, tendo como base os referenciais de pesquisa qualitativa (Bogdan; Biklen, 1994). A coleta de dados foi realizada em dois momentos, na forma de dois estudos independentes, porém articulados. 0 primeiro abrangeu as duas escolas municipais. 0 segundo, por sua vez, focou o processo educacional de alunos com deficiência intelectual matriculados em uma escola especializada estadual. Os quadros a seguir sintetizam as informações sobre os sujeitos participantes dos estudos. Para preservar o anonimato dos mesmos, todos os nomes são fictícios.

5. Uma análise detalhada sobre as diferenças entre os referidos termos e as bases epistemológicas presentes em cada conceito pode ser encontrada em Pletsch (2012).

6. 0 nome de Vygotski aparece na literatura escrito de diferentes maneiras. Neste artigo, adotamos a grafia de acordo com as indicações das obras empregadas no texto.

7. Uma análise aprofundada sobre os aspectos teóricos que fundamentaram a pesquisa podem ser encontradas na obra da defectologia de Vygotski (1997) e nos estudos que vem sendo desenvolvidos pelos grupos de pesquisa coordenados por: Anna Luiza Bustamante Smolka (UNICAMP) e Albertina Mitjáns Martínez e Maria Carmem Villela Rosa (UnB). 
Quadro 1 - Caracterização dos alunos com deficiência intelectual em turmas comuns de escolas regulares da Rede Municipal do Rio de Janeiro

\begin{tabular}{|c|c|c|c|}
\hline Nome do aluno* & Idade & $\begin{array}{c}\text { Nível de } \\
\text { escolaridade }\end{array}$ & $\begin{array}{c}\text { Observações realizadas a partir dos } \\
\text { relatos das professoras }\end{array}$ \\
\hline Maria Rosa & 8 anos & $\begin{array}{c}\text { Primeiro ano } \\
\text { do Ciclo }\end{array}$ & $\begin{array}{l}\text { Apresenta dificuldades na linguagem } \\
\text { oral e recebe suporte educacional } \\
\text { especializado da sala de recursos. }\end{array}$ \\
\hline Maria Clara & 9 anos & $\begin{array}{c}\text { Primeiro ano } \\
\text { do Ciclo }\end{array}$ & $\begin{array}{l}\text { Recebe suporte educacional } \\
\text { especializado da sala de recursos. }\end{array}$ \\
\hline
\end{tabular}

Quadro 2 - Caracterização dos alunos com deficiência intelectual da escola especializada da Rede Estadual de Ensino

\begin{tabular}{|c|c|c|l|}
\hline Nome do aluno & Idade & $\begin{array}{c}\text { Nível de } \\
\text { escolaridade }\end{array}$ & \multicolumn{1}{|c|}{ Observações } \\
\hline Felipe & 8 anos & Ciclo I & $\begin{array}{l}\text { Apresenta dificuldades na } \\
\text { interação social com o grupo em } \\
\text { sala de aula. }\end{array}$ \\
\hline Milena & 9 anos & Ciclo I & $\begin{array}{l}\text { Participativa, mas desatenta em } \\
\text { relação às tarefas escolares. }\end{array}$ \\
\hline Mariana & 6 anos & Ciclo I & $\begin{array}{l}\text { Apresenta grandes dificuldades na } \\
\text { linguagem oral. }\end{array}$ \\
\hline
\end{tabular}

Em ambos os estudos, além da realização de entrevistas semiestruturadas com os professores responsáveis pelos sujeitos alvo dessa pesquisa, aplicamos uma ficha de acompanhamento individual, com o objetivo de avaliar o desenvolvimento escolar destes alunos. A elaboração desse instrumento tomou como base os pressupostos do INDEX do Centre for Studies in Inclusive Education (CSIE), desenvolvido por Booth \& Ainscow (2002), para avaliar o processo de implementação da inclusão escolar e social em diferentes sistemas escolares. Também utilizamos o Referencial sobre Avaliação da Aprendizagem na Área de Deficiência Intelectual (RAADI) (São Paulo, 2008), elaborado pela professora Anna Augusta Sampaio de Oliveira (UNESP/SP).

Para a elaboração e aplicação da ficha de acompanhamento individual, foi importante, ainda, o levantamento da produção sobre deficiência intelectual nas áreas de educação, psicologia e ciências sociais disponível no banco de dados SCIELO-Brasil (Scientific Eletronic Library Online), no período de 1994 até 2009 (Antunes et al., 2010). 0 material foi catalogado e usado como base na análise e discussão dos dados coletados na pesquisa de campo. A ficha de acompanhamento individual possibilitou a elaboração e aplicação do Plano de Desenvolvimento Educacional Individualizado (PDEI), como veremos mais adiante. 


\section{Deficiência intelectual: dimensões sobre a sua escolarização}

Os resultados obtidos em nossas investigações vão ao encontro de dados de pesquisas anteriores sobre a temática e mostram a grande resistência por parte de gestores e professores para a inclusão desses alunos em turmas comuns, mais até do que para outras condições como deficiências físicas e sensoriais (Aguiar, 2003; Santos, 2006; Glat, 2008; Oliveira, 2008; Pletsch, 2010; Redig, 2010; Valentim, 2011). Sem minimizar as dificuldades inerentes à falta de formação ou conhecimentos dos docentes, é preciso levar em consideração a supervalorização das habilidades cognitivas presente nas concepções dos educadores que torna esses sujeitos, em suas percepções, inelegíveis à aprendizagem formal.

A ficha de acompanhamento individual foi aplicada nos dois estudos e resultou na validação destes, proporcionando subsídios para a construção, aplicação e avaliação inicial de outro instrumento, denominado Plano de Desenvolvimento Educacional Individualizado (PDEI). Este foi concebido nos moldes dos planos individuais de inclusão utilizados nas redes escolares de países da Europa e nos Estados Unidos para promover o desenvolvimento e a futura inserção social e laboral de alunos com essa deficiência (Pletsch, 2009; Mclnerney, 2010). Esses referenciais sugerem que a partir do PDEI seja possível promover estratégias pedagógicas individualizadas a serem empregadas para o desenvolvimento de alunos com deficiência intelectual em três dimensões, dependendo da faixa etária e do nível de desenvolvimento e/ou interesse do aluno, a saber: no processo de aprendizagem escolar, nas habilidades sociais e nas habilidades necessárias para a inclusão laboral (Pletsch et al., 2010). A seguir, segue a estrutura básica do PDEl utilizada no planejamento de práticas pedagógicas dirigidas para os alunos com deficiência intelectual:

\section{Quadro 3 - Plano de Desenvolvimento Educacional Individualizado (PDEI)}

\begin{tabular}{|c|c|c|c|c|}
\hline \multicolumn{5}{|c|}{ Plano de Desenvolvimento Educacional Individualizado (PDEI) } \\
\hline \multicolumn{2}{|l|}{ Nome: } & \multicolumn{2}{|c|}{ Nascimento/ldade: } & \\
\hline \multicolumn{2}{|c|}{ Data do planejamento: } & \multicolumn{2}{|c|}{ Grupo/série: } & \\
\hline $\begin{array}{l}\text { Capacidades, } \\
\text { interesses a } \\
\text { serem desenvol- } \\
\text { vidos (O que sabe? } \\
\text { Do que gosta?) }\end{array}$ & $\begin{array}{l}\text { Necessidades e } \\
\text { prioridades } \\
\text { (O que aprender/ } \\
\text { ensinar?) }\end{array}$ & $\begin{array}{l}\text { Metas e prazos } \\
\text { para a realização } \\
\text { e intervenção } \\
\text { (Em quanto } \\
\text { tempo?) }\end{array}$ & $\begin{array}{l}\text { Recursos a } \\
\text { serem utilizados } \\
\text { (0 que usar para } \\
\text { ensinar? Como?) }\end{array}$ & $\begin{array}{l}\text { Profissionais } \\
\text { envolvidos na } \\
\text { aplicação da } \\
\text { proposta } \\
\text { (Quem?) }\end{array}$ \\
\hline
\end{tabular}

Fonte: Pletsch et al. (2010) e Marin et al. (2011). 
Ainda sobre a escolarização de alunos com deficiência intelectual, no caso das escolas da rede municipal do Rio de Janeiro, além do mapeamento acima mencionado, foi possível analisar também as práticas pedagógicas destinadas para os alunos alvo da pesquisa por meio de procedimentos de observação participante lcom registro em diário de campol. Esta imersão no cotidiano escolar desvelou não só as contradições, mas também, acima de tudo, a complexidade do processo de inclusão de alunos com deficiência intelectual, particularmente na esfera das práticas pedagógicas. Chama a atenção, conforme já sinalizado em estudos anteriores, sobre formação de professores (Mafezoni, 2002, 2011; Jesus, 2007, 2009; Fontes, 2009; Oliveira; 2010; Kassar, 2009; Glat; Pletsch, 2010), a falta de conhecimentos dos docentes sobre as especificidades de desenvolvimento dos sujeitos por um lado, e de estratégias de flexibilização e/ou adaptação curricular por outro.

Os dados mostraram também que as práticas pedagógicas e as atividades acadêmicas que ocorrem em classes regulares não sofrem qualquer transformação ou adaptação para atender às necessidades educacionais específicas desses alunos. Ou seja, os professores continuam seguindo a proposta didática tradicional, pautada numa concepção dicotômica do processo ensino e aprendizagem - normal e especial (anormal) (Glat; Blanco, 2007; Beyer, 2008), sem levar em consideração a diversidade da turma.

As tentativas de modificação na estrutura curricular verificadas consistiam apenas em pequenos ajustes, voltados para uma "facilitação" da tarefa, o que acabava por minimizar as possibilidades de aprendizagens superiores - para usar um termo vigotskiano. As atividades escolares apresentadas para os alunos participantes dessa pesquisa e para seus colegas, de maneira geral - tanto no contexto educacional comum quanto no especializado -, consistiam, na maior parte das vezes, em tarefas elementares como recortar, colar, pintar, copiar, ou seja, atividades que não favoreciam o desenvolvimento de habilidades cognitivas mais elaboradas, necessárias para a construção de conceitos científicos que envolvem conhecimentos abstratos (por exemplo, a relação entre o signo representado pelo número um e a quantidade que ele representa).

Estabelecer esse tipo de relação conceitual é uma das principais dificuldades de pessoas com deficiência intelectual, pois tal construção demanda generalização e abstração, habilidades para as quais eles têm dificuldade, segundo verificado na pesquisa de doutorado realizada por Pletsch (2010). Para proporcionar este tipo de desenvolvimento cognitivo, devem ser oferecidas atividades que desenvolvam justamente essas capacidades. Entretanto, não foi essa a realidade constatada. Ao contrário, pode-se dizer até que, de certa forma, a escola - seja regular, seja especial - contribui para maior "cristalização" da deficiência, em vez da superação desta. Vigostki já alertava para esse problema lapud Veer; Valsier, 2001, p. 87), ao afirmar que “o potencial do 
desenvolvimento para crianças defeituosas [refere-se às crianças com alguma deficiência] deveria ser buscado na área das funções psicológicas superiores", e não das elementares. A este respeito podemos acrescentar que a aprendizagem "não ocorre de maneira espontânea, mas sim a partir da interação e do desenvolvimento de práticas curriculares planejadas e sistematizadas de forma intencional" (Pletsch, 2010, p. 187).

Consonantes com a representação social do deficiente intelectual como incapaz de aprendizagens complexas superiores, as professoras parecem adotar uma atitude de pouca expectativa e exigência, aceitando "o pouquinho que eles fazem já está bom”, já que "pelo menos eles estão na escola se socializando", conforme colocaram duas docentes em entrevista. Por outro lado, a preocupação com a aquisição da leitura e da escrita era uma constante nos relatos das professoras. Uma delas chegou a mencionar que a aluna Maria Clara "está muito bem socializada, mas, em termos de aprendizagem, ela nem está alfabetizada” (professora em entrevista). Pesquisas desenvolvidas por Silva (2000) também destacaram a preocupação dos docentes em relação à alfabetização de alunos com deficiência intelectual.

Aliás, desde os anos 1980 tem havido um debate intenso sobre o processo e a alfabetização, ou seja, a codificação e decodificação dos códigos da leitura e da escrita. Mais recentemente entrou em pauta nas discussões a questão do "letramento", que se volta para a funcionalidade ou função social da alfabetização (Monroy, 2003; Garcia, 2005; Carvalho, 2006; Sato, 2008). As dificuldades dos alunos de escolas públicas no que tange ao processo de alfabetização vêm sendo um item prioritário nas agendas dos diferentes gestores da Educação. A inclusão de alunos com deficiência intelectual em turmas em que já há um grande contingente de "analfabetos funcionais", sem programas efetivos de intervenção, só vem aumentar a desmotivação dos professores. Certamente estudos nessa direção são urgentes.

Em suma, apesar dos avanços científicos e da consolidação de políticas públicas seguindo os princípios da educação inclusiva, as práticas pedagógicas e a cultura escolar que se observa no cotidiano das instituições públicas de ensino não sofreram ressignificação. Este cenário acaba prejudicando o processo de ensino e aprendizagem de alunos com necessidades especiais, sobretudo daqueles com dificuldades cognitivas, como os sujeitos com deficiência intelectual. Os dados coletados mostram claramente que não têm ocorrido transformações nas oportunidades e na qualidade dos programas educacionais destinados a estes alunos, pelo menos nos casos analisados. Diversos pesquisadores têm apontado nessa mesma direção (Miranda, 2003; Pieczkowski, 2003; Possidio, 2004; Garcia, 2005; Ribeiro, 2006; Pletsch, 2010; Redig, 2010).

Outra variável analisada diz respeito ao papel da Educação Especial na avaliação, encaminhamento e promoção da aprendizagem de alunos com deficiência intelectual. 
A pesquisa mostrou que os professores do ensino comum não assumem, na prática, a responsabilidade didática pelos alunos com deficiências incluídos em suas turmas. Essa realidade foi verificada também em pesquisa recente em outras duas redes de ensino públicas municipais do Estado do Rio de Janeiro (Glat; Pletsch, 2011).

Pode-se dizer que, no caso dos alunos com deficiência intelectual, esta situação só é ampliada, já que este sujeito continua sendo considerado "da Educação Especial”, o que representa um papel determinante na vida escolar da maioria desses sujeitos. Enquanto a Educação Especial continuar - de fato, mesmo que não no discurso atuando como um sistema paralelo, pouco progresso se fará na aprendizagem, desenvolvimento e inclusão destes alunos. Mendes (2006), Oliveira (2008), Fontes (2009), entre outros, ratificam essa posição, ao discutir a importância do trabalho colaborativo entre o especialista da Educação Especial com o professor regente da turma comum em que estão matriculados alunos com deficiência intelectual.

No que tange à avaliação de alunos com déficit cognitivo, ficou evidente nos relatos das professoras o quanto a concepção de deficiência intelectual ainda é impregnada pelo modelo médico, em uma visão estática das possibilidades de aprendizagem e desenvolvimento desses sujeitos. 0 diagnóstico clínico continua sendo usado como referência para as práticas educacionais, apesar de as diretrizes normativas oficiais pregarem a "avaliação educacional". Uma das gestoras entrevistada disse que: "para que um aluno possa se beneficiar de atendimento educacional especializado no contraturno, é preciso que ele tenha um laudo de deficiência".

Tendo como referencial a concepção clínica de avaliação, certamente as práticas pedagógicas não serão positivas para o processo de aprendizagem, uma vez que focalizam na deficiência e não no processo educacional no qual esse aluno está inserido. Oliveira (2008), em pesquisa realizada em escola pública municipal considerada de excelência, constatou que os professores não se sentiam capazes de avaliar as atividades acadêmicas dos alunos com deficiência intelectual incluídos em suas turmas. A maioria preocupava-se com a aferição dos conteúdos apreendidos - ou seja, o produto -, e não com o processo de ensino e aprendizagem em si. Assim, os alunos com necessidades educacionais especiais acabavam ficando sem uma avaliação educacional, uma vez que não podiam ser medidos pelos padrões exigidos do restante da turma, mas também não havia uma alternativa diferenciada de avaliação da aprendizagem. Aguiar (2003), Schütz (2006), Valentim (2011) e Oliveira (2011) em suas análises seguem a mesma direção.

Ainda sobre o processo avaliativo, as contribuições de Beyer (2005) são importantes, ao sinalizarem os aspectos positivos e negativos desse processo. Para esse autor, a avaliação focada no déficit do aluno provoca o rebaixamento das expectativas dos professores. Logo, os investimentos pedagógicos acabam sendo rebaixados, focando, 
de maneira geral, atividades elementares concretas e não propondo estratégias que busquem o desenvolvimento cognitivo superior desses alunos - aspecto evidenciado em nossa pesquisa de campo.

De acordo com o referido autor, as práticas avaliativas são parciais, focalizam única e exclusivamente o aluno, sem considerar fatores atrelados à prática do professor no que se refere ao seu empenho de ensinar, as circunstâncias do ambiente escolar, os recursos de ensino disponíveis na escola, entre outros aspectos. Para superar tais dificuldades do processo avaliativo focado nas limitações do sujeito, Beyer sugere uma avaliação dinâmica com base no trabalho de Vigotski, que sugere uma avaliação analítica e formativa que leve em consideração as condições individuais do sujeito tendo como base os preceitos conceituais da zona de desenvolvimento proximal entendido como

[...] a distância entre o nível de desenvolvimento real, que se costuma determinar através da solução independente de problemas, e o nível de desenvolvimento potencial, determinada através da solução de problemas sob a orientação de um adulto ou em colaboração com companheiros mais capazes (Vigotski, 2003, p. 112).

Em síntese, os dados colhidos por meio das fichas de acompanhamento individual e do PDEl, bem como nas observações de campo em turmas comuns (consideradas inclusivas) e em salas da instituição especializada, apoiados nas entrevistas das professoras, evidenciaram a precariedade do processo ensino e aprendizagem oferecido a alunos com deficiência intelectual, assim como do processo e estratégias avaliativas empregadas nessas instituições. Não resta dúvida de que a impugnação do rótulo de "aluno especial" ou "deficiente mental" acaba por minimizar os investimentos pedagógicos para o desenvolvimento desses sujeitos.

\section{Considerações finais}

Nosso objetivo nesse artigo foi discorrer sobre os resultados das investigações que temos realizado nos últimos anos no campo da escolarização de alunos com deficiência intelectual. Nesse sentido, os resultados de nossas investigações evidenciam, em ambos os contextos educacionais analisados, as contradições e dificuldades vivenciadas pelos professores para desenvolver propostas educacionais com desenvolvimento e aprendizagem para alunos com deficiência intelectual.

A partir das reflexões realizadas, pode-se afirmar que, mais do que reestruturar práticas e/ou propor ajustes no currículo - o que é comumente sugerido pelas políticas 
públicas -, é preciso disponibilizar conhecimentos teórico-práticos e suporte aos profissionais da Educação para que possam realizar mediações pedagógicas que favoreçam o processo de ensino e aprendizagem de todos os alunos, sobretudo daqueles que apresentam necessidades educacionais especiais. A educação efetiva de fato e de direito de alunos com deficiência intelectual em contexto "inclusiva" necessita de uma transformação na cultura escolar. A partir dessas mudanças será possível elaborar práticas pedagógicas e novas "relações educacionais que possibilitem aos alunos [...] compensar suas dificuldades e desenvolver suas funções psicológicas superiores sob a forma de apropriação dos conteúdos da experiência humana" (Pletsch, 2010, p. 238).

Não menos prioritária é a reformulação curricular e conceitual dos cursos de formação de professores, pois a maioria dos cursos de pedagogia, na discussão sobre a escolarização de alunos com deficiência intelectual em diferentes contextos educacionais, ainda não incorporaram em suas grades conteúdos e atividades que possibilitem aos professores em atuação e futuros professores reverem suas concepções a respeito do processo de ensino e aprendizagem de alunos com deficiências (Glat; Pletsch, 2011). Ou seja, é preciso desviar o foco da dificuldade de aprendizagem como um problema intrínseco do aluno, para compreendê-la como fruto das interações sociais e pedagógicas estabelecidas em sala de aula.

No que se refere à aplicação e validação da ficha de acompanhamento, o estudo mostrou que a mesma é positiva para acompanhar as trajetórias escolares e o processo de desenvolvimento educacional de alunos com deficiência intelectual. A partir de sua aplicação, novas estratégias e instrumentos para avaliar e acompanhar o processo educacional de alunos com deficiência intelectual foram elaborados, como é o caso do Plano de Desenvolvimento Educacional Individualizado (PDEI).

O PDEI mostrou-se como uma importante estratégia para favorecer a inclusão educacional desses alunos. No entanto, apesar das evidências positivas, novas pesquisas devem ser realizadas para ampliar e validar esses instrumentos ou outros similares, que poderão contribuir significativamente com a implementação das atuais políticas de inclusão escolar, promovendo novos parâmetros para o atendimento educacional especializado de alunos com deficiência intelectual e outras deficiências incluídos em classes comuns. Mas, sobretudo, instrumentos dessa natureza poderão auxiliar no planejamento de práticas pedagógicas que promovam o processo de ensino e aprendizagem desses alunos e seu consequente desenvolvimento.

Por último, é preciso lembrar que pesquisas de cunho qualitativo nunca trazem conclusões definitivas. Todavia, espera-se que as questões brevemente levantadas neste texto possam contribuir com o campo científico da Educação e, particularmente, o desenvolvimento social e a escolarização de pessoas com deficiência intelectual. 


\section{Referências}

ALONSO, Miguel Angel Verdugo; SCHALOCK, Robert L. Últimos avances en el enfoque y concepción de las personas com discapacidad intelectual. In: Revista Española sobre Discapacidad Intelectual, v. 41 (4), n² 236, p. 7-21, Espanha, 2010.

ASSOCIAÇÃO AMERICANA DE RETARDO MENTAL. Retardo mental - definição, classificação e sistemas de apoio (2002). 10ª edição. (tradução Magda França Lopes). Editora: ARTMED, Porto Alegre, 2006.

ASSOCIAÇÃO AMERICANA DE DEFICIÊNCIA INTELECTUAL E DESENVOLVIMENTO. Disponível em.:< http://www.aaidd.org/>. Acesso em: mar. 2011.

AGUIAR, Ana Marta Bianchi de. Caminhos e descaminhos da avaliação do deficiente mental. $112 f$. Dissertação (Mestrado em Educação) -Universidade Federal do Espírito Santo, Espírito Santo, 2003. ANTUNES, Kátia Cristina Vargas. et al. Uma análise da produção científica sobre deficiência intelectual na base de dados Scielo: o processo de ensino aprendizagem. In: Anais do IV Congresso Brasileiro de Educação Especial e IV Encontro Nacional de Pesquisadores em Educação Especial, São Carlos/SP, p. 1-17, 2010.

BEYER, Hugo Otto. Inclusão e avaliação na escola de alunos com necessidades educacionais especiais. Editora Mediação. Porto Alegre, 2005.

. 0 projeto político-pedagógico da educação inclusiva e a gestão educacional: reflexões com a área de Educação Especial da Secretaria de Educação do Estado do Rio grande do Sul. In: FREITAS, Soraia Napoleão (orgs.). Tendências contemporâneas de inclusão, Editora da UFSM, Santa Maria, p. 77-90, 2008.

BRASIL. Política Nacional de Educação Especial na Perspectiva da Educação Inclusiva. Brasília, janeiro de 2008.

. Decreto 6.571, de 17 de setembro de 2008. Diário Oficial [da] Presidência da República do Brasil. Disponível em: < http://www.planalto.gov.br/ccivil_03/_ato2007-2010/2008/Decreto/D6571.htm.> Acesso: outubro de 2011.

. Diretrizes Operacionais do Atendimento Educacional Especializado na Educação Básica, modalidade Educação Especial. Brasília, 2009.

. Decreto n 7.611, de 17 de novembro de 2011. Diário Oficial [da] Presidência da República do Brasil. Dispo nível em: <http://www.planalto.gov.br/ccivil_03/_Ato2011-2014/2011/Decreto/D7611.htm >. Acesso: outubro de 2011.

B00TH, Tony; AINSCOW, Mel. Index for inclusion: developing learning and participation in Schools. Bristol, Centre for Studies in incluive Education, 2002.

BOGDAN, Robert; BIKLEN, Sari. Investigação qualitativa em educação - uma introdução à teoria e aos métodos. Porto/Portugal: Porto Editora, 1994.

CARVALHO, Maria de Fátima. Conhecimento e vida na escola: convivendo com as diferenças. Autores Associados de Campinas/ SP e Unijuí de ljuí/RS, 2006.

FONTES, Rejane de Souza. Ensino colaborativo: uma proposta de educação inclusiva. Araraquara/SP: Editora Junqueira\&Marin, 2009. 
JESUS, Denise Meyrelles. Vozes e narrativas na ação grupal: trajetórias de formação de professorespesquisadores na perspectiva da inclusão escolar. In: ; BAPTISTA, Claudio Roberto; BARRETO, Maria Aparecida Santos Corrêa; VICTOR, Sônia Lopes (org.). Inclusão, práticas pedagógicas e trajetórias de pesquisa. Porto Alegre: Editora Mediação, 2007, p. 66-175.

. Políticas de inclusão escolar no Espírito Santo: tecendo caminhos teórico-metodológicos. In: BAPTISTA, Claudio Roberto; JESUS, Denise Meyrelles; (org.). Avanços em políticas de inclusão o contexto da educação especial no Brasil e em outros países. Porto Alegre: Editora Mediação, 2009, p. 45-56.

GLAT, Rosana; BLANCO, Leila de M. Vilela. Educação Especial no contexto de uma Educação Inclusiva. In: GLAT, Rosana (org.). Educação Inclusiva: cultura e cotidiano escolar. (Coleção Questões atuais em Educação Especial, v. VI). Rio de Janeiro: Editora Sete Letras, 2007, p. 15-35.

PLETSCH, Márcia Denise. Diferentes dimensões do processo de inclusão escolar de alunos com necessidades educacionais especiais do Município do Rio de Janeiro. In: ANACHE, Alexandra Ayach ; OSÓRIO, Antônio Carlos do N. Da Educação Especial à educação na diversidade - escolarização, práticas e processos. Campo Grande/MS: Editora da UFMS, 2010, p. 89-106.

A Educação Especial no contexto da Educação Inclusiva: diretrizes políticas e ações pedagógicas. Relatório PROCIÊNCIA, Rio de Janeiro, 2011.

PLETSCH, Márcia Denise. Inclusão escolar de alunos com necessidades educacionais especiais. (Série Pesquisa em Educação). Rio de Janeiro: Editora EduERJ, 2011.

GARCIA, Valéria Paiva Casasanta. Prática pedagógica e necessidades educacionais especiais: a relação diádica em sala de aula. 268f . Dissertação (Mestrado em Educação) -Universidade Federal de Uberlândia, Uberlândia/MG, 2005.

KASSAR, Mônica de Carvalho Magalhães. Ciência e senso comum no cotidiano das classes especiais. 2. ed. Campinas/SP: Papirus, 2009.

VIANNA, Marcia Marin; PLETSCH, Márcia Denise; MASCARO, Cristina Angélica. A escolarização de alunos com deficiência intelectual: um estudo sobre o Plano de Desenvolvimento Psicoeducacional Individualizado. Rio de Janeiro, 2011. No prelo.

MAFEZONI, Andressa. 0 processo de escolarização de alunos com deficiência mental incluídos nas séries finais do ensino fundamental. 2002. 144 f. Dissertação (Mestrado em Educação)-Universidade Federal do Espírito Santo, Vitória/ES, 2002.

O processo de formação inicial do professor para a perspectiva de inclusão escolar: especialistas em Educação Especial ou generalistas? In: PLETSCH, Marcia Denise \& DAMASCENO, Allan (Orgs.). Educação Especial e inclusão escolar: reflexões sobre o fazer pedagógico. Rio de Janeiro: Editora Edur, 2011.

MARTINS, Lúcia de Araújo Ramos. Integração escolar do portador de síndrome de Down: um estudo sobre a percepção dos educadores. Revista Brasileira de Educação Especial, Piracicaba, v. 3, nº. 5 , p. 73-85, 1999.

MCLNERNEY, Claudia. Intervenção precoce e acompanhamento nas escolas. Palestra ministrada na FAETEC em 30 de março de 2010. 
MENDES, Enicéia Gonçalves . A radicalização do debate sobre inclusão escolar no Brasil. In: Revista Brasileira de Educação, v. 11, nº 33, p. 387-405, Autores Associados, 2006.

MIRANDA, Arlete Aparecida Bertoldo. A prática pedagógica do professor de alunos com deficiência mental. Tese (Doutorado em Educação)-Universidade Metodista, Piracicaba/SP, 2003.

MONROY, Ângela. Desenvolvimento e aperfeiçoamento de habilidades adaptativas como facilitadora da inclusão social de alunos com deficiência mental: uma proposta de formação continuada de professores. 295f. Tese (Doutorado em Pedagogia aplicada)-Universidade Autónoma de Barcelona, Barcelona, 2003.

ORGANIZAÇÃO MUNDIAL DE SAÚDE. Classificação internacional de funcionalidade, incapacidade e saúde. São Paulo/SP: Editora da Universidade de São Paulo, 2003.

OLIVEIRA, Anna Augusta Sampaio de. Adequações curriculares na área da deficiência intelectual: algumas reflexões. In: OLIVEIRA, Anna Augusta Sampaio; OMOTE, Sadao; GIROTO, Claudia Regina Mosca. Inclusão Escolar: as contribuições da Educação Especial. São Paulo: Editora Fundepe e Cultura Acadêmica, 2008, p. 129-154.

Aprendizagem escolar e deficiência intelectual: a questão da avaliação curricular. In: PLETSCH, Marcia Denise; DAMASCENO, Allan (org.) Educação Especial e Inclusão Escolar: Reflexões sobre o fazer pedagógico. Seropédica, RJ: Ed. da UFRRJ, 2011.

OLIVEIRA, Mércia Cabral de. Avaliação de necessidades educacionais especiais: construindo uma nova prática educacional. 157f. Dissertação (Mestrado em Educação) -Universidade do Estado do Rio de Janeiro (UERJ), 2008.

PLETSCH, Marcia Denise. O plano de desenvolvimento educacional individualizado como estratégia para a escolarização de alunos com deficiência mental. Palestra proferida para professores da Secretaria Municipal de Angra dos Reis/RJ. 2009.

Repensando a inclusão escolar: diretrizes políticas, práticas curriculares e deficiência intelectual. Editoras NAU \& EDUR, Rio de JANEIRO, 2010.

. GLAT, Rosana; VIANNA, Marcia Marin ; MASCARO, Cristina Angélica de; CRUZ, Mara . Plano de Desenvolvimento Psicoeducacional Individualizado (PDPI): estratégia para favorecer o processo de ensino e aprendizagem de alunos com deficiência intelectual. In: Anais do IV Congresso Brasileiro de Educação Especial e IV Encontro Nacional de Pesquisadores em Educação Especial, 2010, p. 1-10.

Uma análise das bases epistemológicas contidas nos conceitos de deficiência mental e intelectual. Rio de Janeiro, 2012. Mimeografado.

PIECZKOWSKI, Tania Mara Zancanaro. 0 processo de integração/inclusão de alunos com necessidades educacionais especiais - deficiência mental em escolas regulares do município de Chapecó-SC. 138 f. Dissertação (Mestrado em Educação)-Universidade de Passo Fundo/RS, 2003.

POSSIDIO, Ana Lúcia Macedo de. Inclusão: do pensar ao agir no cotidiano escolar. 117f. Dissertação (Mestrado em Educação)-Universidade Federal do Espírito Santo, Vitória/ES, 2004.

RAMALDES, Cíntia Rosana. A relação entre informação e trabalho pedagógico de professores de alunos com deficiência mental na rede municipal de ensino de Belo Horizonte. 157f. Dissertação (Mestrado em Ciência da Informação)-Universidade Federal de Minas Gerais, Belo Horizonte/MG, 2004. 
REDIG, Annie Gomes. Ressignificando a Educação Especial no contexto da educação inclusiva: a visão de professores especialistas. 183 f. Dissertação (Mestrado em Educação) -Universidade do Estado do Rio de Janeiro (UERJ), 2010.

RIBEIRO, Júlia Cristina Coelho. Significações na escola inclusiva - um estudo sobre as concepções e práticas de professores envolvidos com a inclusão escolar. 226f. Tese (Doutorado em Psicologia)Universidade de Brasília (UNB/DF), Brasília, 2006.

SATO, Denise Tamaê Borges. A inclusão da pessoa com síndrome de Down: identidades docentes, discursos e letramentos. Dissertação (Mestrado em Lingüística)-Universidade de Brasília, Brasília, 2008.

SANTOS, Roseli Albino dos. Processos de escolarização e deficiência: trajetórias escolares singulares de ex-alunos de classe especial para deficientes mentais. 197f. Tese (Doutorado em Educação)Pontifícia Universidade Católica de São Paulo, São Paulo, 2006.

SÃO PAULO. Referencial sobre avaliação da aprendizagem na área de deficiência intelectual. Elaborado por Anna Augusta Sampaio de Oliveira, Secretaria Municipal de Educação, São Paulo, 2008.

SILVA, Fabiany Tavares. Processos de ensino na educação dos deficientes mentais. In: 23a Reunião Anual da ANPEd, Caxambu/MG, 2000, p. 1-16.

SCHÜTZ, Maria Rosa Rocha dos Santos. Avaliação escolar como instrumento de mediação da aprendizagem na educação inclusiva: desafios no cotidiano escolar. 132f. Dissertação (Mestrado em Educação)-Universidade do Vale do Itajaí (UNIVALE), Itajaí, 2006.

SCHALOCK, Robert L. et al. El Nuevo nombre del retraso mental: comprendiendo el cambio al término discapacidad intelectual. Revista Española sobre Discapacidad Intelectual, 38 (4), Espanha, 2007.

VALENTIM, Fernanda Dourado. Inclusão de alunos com deficiência intelectual: considerações sobre avaliação de aprendizagem escolar. 122 f. Dissertação (Mestrado em Educação)-Universidade Estadual Paulista Júlio de Mesquita Filho (UNESP), São Paulo, 2011.

VEER, René Van Der; VALSIEER, Jaan Vygostky: uma síntese. $4^{\mathrm{a}}$ ed.São Paulo: Editora Loyola, 2001. WEHMEYER, Michel L. et al. La deficiência intellectual. In: Center for International Rehabilitation. Disponível em: <http://cirrie.buffalo.edu/encyclopedia/es/article/15/>. Acesso em: mar. 2011.

VIGOTSKI, Lev Semenovich. A formação social da mente. São Paulo: Editora Martins Fontes, 2003. . Fundamentos da defectologia (Obras escogidas), volume V. Madrid: Visos, 1997.

Recebido em novembro de 2011.

Aprovado em dezembro de 2011. 
Marcia Denise Pletsch, doutora em Educação (UERJ). Professora do Instituto Multidisciplinar da Universidade Federal Rural do Rio de Janeiro. Coordenadora do Observatório de Educação Especial e inclusão educacional: políticas públicas e práticas curriculares e professora do Programa de Pós-Graduação em Educação, Contextos Contemporâneos e Demandas Populares da mesma universidade. Publicação Recente: Repensando a inclusão escolar: diretrizes políticas, práticas curriculares e deficiência intelectual (Rio de Janeiro: NAU/EDUR, 2010). E-mail: marcia_pletschdyahoo.com.br

Rosana Glat, doutora em Psicologia (FGV). Professora e diretora da Faculdade de Educação da Universidade do Estado do Rio de Janeiro. Coordenadora do Grupo de Pesquisa Inclusão e aprendizagem de alunos com necessidades educacionais especiais: práticas pedagógicas, cultura escolar e aspectos psicossociais e professora do Programa de Pós-Graduação em Educação da mesma universidade. Publicação recente: Inclusão escolar de alunos com necessidades educacionais especiais (co-autoria com PLETSCH, Marcia. Rio de Janeiro: EDUERJ, 2011). E-mail: rglataterra.com.br 